Etnográfica

Revista do Centro em Rede de Investigação em

Antropologia

vol. 25 (3) | 2021

Vol. 25 (3)

\title{
"El arte callejero no es delito": procesos de politización de la cultura en la Ciudad de Buenos Aires, Argentina
}

"Street art is not a crime": Processes of politicization of culture in the City of Buenos Aires, Argentina

\section{Julieta Infantino}

\section{Q OpenEdition}

\section{Journals}

Edición electrónica

URL: https://journals.openedition.org/etnografica/10614

DOI: 10.4000/etnografica.10614

ISSN: 2182-2891

\section{Editor}

Centro em Rede de Investigação em Antropologia

Edición impresa

Fecha de publicación: 1 octubre 2021

Paginación: 657-679

ISSN: 0873-6561

Referencia electrónica

Julieta Infantino, «"El arte callejero no es delito": procesos de politización de la cultura en la Ciudad de Buenos Aires, Argentina», Etnográfica [En línea], vol. 25 (3) | 2021, Publicado el 29 octubre 2021,

consultado el 10 enero 2022. URL: http://journals.openedition.org/etnografica/10614 ; DOI: https:// doi.org/10.4000/etnografica.10614

\section{(c) (7) (8)}

Etnográfica is licensed under a Creative Commons Attribution-NonCommercial 4.0 International License. 


\section{"El arte callejero no es delito": procesos de politización de la cultura en la Ciudad de Buenos Aires, Argentina}

\section{Julieta Infantino}

En este trabajo parto de una investigación etnográfica desarrollada junto a colectivos de artistas callejeros de la ciudad de Buenos Aires y focalizo en un evento particular: el intento de regulación de la actividad artística en el espacio público desde el gobierno local durante 2018 y la movilización en rechazo que activó, demandando el derecho al trabajo artístico callejero bajo la consigna "el arte callejero no es delito". Propongo analizar cómo este proceso implicó resignificaciones en las modalidades de pensar el rol social/político del arte y los artistas, así como el papel del Estado en relación al arte y la cultura. Dichas transformaciones que venían desplegándose desde años anteriores fueron generando procesos de politización de diversos actores del campo cultural en relación a demandas por derechos, políticas y legislación. Sostengo que la resistencia que se desató ante el intento de regularización/penalización del arte callejero debe ser analizada en vínculo con estos antecedentes de organización político-colectiva en el campo cultural, así como con una resignificación de las maneras de conceptualizar la potencialidad política de las prácticas artísticas, la independencia/autogestión y los derechos culturales.

PALABRAS CLAVE: artistas callejeros, disputas político-culturales, organización colectiva, independencia, politicidad del arte, derechos culturales.

"Street art is not a crime": Processes of politicization of culture in the City of Buenos Aires, Argentina - In this paper I recover an ethnographic research developed with groups and organizations of artists from Buenos Aires and focus on a particular event: the intention of the local government to regulate the artistic activity in the public sphere that took place during 2018 and the mobilization in rejection that it activated, demanding the right to street artwork under the slogan "street art is not a crime". I analyze how this process implied resignifications in the ways of thinking the social/political role of art and artists as well as the role of the State in relation to art and culture. These transformations that had been unfolding since previous years activated politicization processes of various actors in the cultural field in relation to demands for cultural rights, policies and legislation. I argue that the resistance that was unleashed in the face of the attempt to regularize/penalize street art must be analyzed in connection with this background of political-collective organization in the cultural field as well as with a resignification of the ways of conceptualizing the political potential of artistic practices, the independence/self-management and cultural rights. 
KEYWORDS: street artists, political-cultural disputes, collective organization, independence, art politicity, cultural rights.

INFANTINO, Julieta (julietainfantino@gmail.com) - Consejo Nacional de Investigaciones Científicas y Tecnológicas (Conicet), Sección de Antropología Social, Instituto de Ciencias Antropológicas, Facultad de Filosofía y Letras. Universidad de Buenos Aires, Argentina.

\section{INTRODUCCIÓN}

A mediados de 2018 el Gobierno de la Ciudad Autónoma de Buenos Aires (en adelante $\mathrm{CABA}$ ) presentó un proyecto de reforma del código contravencional porteño - legislación que regula la actuación en el espacio público urbano -, que, principalmente a través de la figura de "ruidos molestos", afectaba a los/ as artistas de la ciudad que trabajan en el espacio callejero, habilitando denuncias anónimas, arresto, incautación de materiales de trabajo y pago de elevadas multas. Este proyecto generó un gran rechazo entre los/as artistas y activó una amplia movilización que abogaba por el derecho al arte callejero y particularmente a la consigna "el arte callejero no es delito".

El proceso de disputa ante la reforma del código contravencional no sólo implicó movilizaciones y resistencia - performances callejeras, divulgación en medios de comunicación y redes sociales - sino que también consolidó la organización colectiva que venía gestándose en años anteriores para demandarle al Estado la garantización del derecho al trabajo callejero, al uso de la ciudad, a la libertad de expresión en el espacio público y a la valorización de las prácticas artísticas autogestivas e independientes como constitutivas del espacio público urbano y como patrimonio de la ciudad.

Propongo analizar cómo este proceso se entrelaza con transformaciones en las modalidades de pensar el rol social/político del arte y los artistas, la disputa - político-cultural así como la función del Estado en relación al arte y la cultura. Dichas transformaciones que venían desplegándose desde años anteriores fueron generando procesos de politización de diversos actores del campo cultural - tanto a nivel local como nacional - en relación a demandas por derechos y legislación; politización que fue adoptando características particulares y "novedosas" que serán objeto de indagación en este trabajo. Considero que la movilización y resistencia que se desataron ante la reforma del código contravencional porteño durante 2018 deben ser analizadas en vínculo con estos antecedentes, así como con una expansión/resignificación de las maneras de conceptualizar la potencialidad política de las prácticas artísticas y ciertos 
conceptos asociados a dicha potencialidad como los de independencia/autogestión con los que los/as artistas se identificaron e identifican.

Parto de la investigación etnográfica que vengo desplegando junto a organizaciones de artistas desde principios de la década ${ }^{1}$ y estructuro el trabajo del siguiente modo: en primer lugar, analizo las maneras en las que se fueron gestando diversos colectivos y organizaciones artísticas locales a partir de la década de 2010 en vínculo con un contexto político nacional y regional que abogaba por políticas (culturales) participativas que movilizaran otros modos de relación entre artistas y Estado. Estudiaré aquí como este contexto fue habilitando diversas demandas por legislación y políticas culturales que respondan a las necesidades de los propios hacedores culturales. Así, diferentes colectivos de artistas independientes de la ciudad fueron articulando sus luchas con referentes del campo político diseñando propuestas legislativas para fomentar marcos de derechos frente a vacíos legales que habilitaban, por ejemplo, las clausuras de espacios independientes y la criminalización de artistas callejeros. En este primer apartado, me interesa también analizar como a partir de la asunción de un nuevo gobierno a nivel nacional (2015-2019) se fue consolidando un ámbito de disputa política en el campo de la cultura, que específicamente en la CABA, adquirió particularidades y gran visibilidad.

Así, en segundo lugar analizaré las modalidades que adquirió la disputa político-cultural en 2018 ante la reforma del código contravencional porteño. Me interesa evidenciar aquí cómo se entrelazaron movilizaciones y protestas artístico-callejeras con otras estrategias vinculadas a negociaciones al interior del ámbito político: reuniones con legisladores, participación en los debates parlamentarios, presentación de proyectos de ley alternativos, entre otros.

En último lugar, consideraré algunos ejes teóricos para abordar ciertas cuestiones que considero claves para comprender el caso estudiado: las resignificaciones en las modalidades de pensar la potencialidad política del arte que otorgó nuevos sentidos a la idea de resistencia/independencia en los vínculos artistas-Estado y la importancia de lo colectivo - que a su vez implica

1 Desde el año 1999 trabajo con artistas circenses en la CABA y en el país. A lo largo de estos años abordé diversas temáticas teóricas como la resignificación estilística de géneros artísticos, la dimensión laboral del arte, las políticas culturales, entre otras. Realicé mi investigación principalmente desde un abordaje antropológico que incluyó diversos trabajos de campo etnográficos, observación participante, entrevistas. También y sobre todo en los últimos años, trabajé desde metodologías relacionadas con lo que suele denominarse antropología en colaboración o antropología por demanda en vínculo con mi posición de investigadora/asesora/colaboradora/militante, analizando el modo en el que trabajé junto a los y las artistas para promover y disputar políticas que mejoren las condiciones de producción y reproducción del arte circense (Infantino 2017, 2018). Específicamente en este artículo retomo el trabajo de campo que realicé junto a los artistas circenses callejeros con los que venía trabajando en su vínculo con otros colectivos artísticos de la ciudad con los que fueron articulando sus luchas y demandas en la última década. 
movilidades entre disensos y consensos entre los artistas - en los procesos de disputa política.

\section{ORGANIZACIÓN ARTÍSTICA COLECTIVA.}

\section{LAS DEMANDAS POR LEGISLACIÓN}

Resulta imprescindible brindar algunos datos acerca del contexto político nacional argentino para comprender los procesos de politización de la cultura (Wright 1998) en la CABA y las modalidades que fue adoptando la disputa política en torno a lo cultural en la última década. La CABA fue gobernada por Mauricio Macri en dos mandatos sucesivos (2007-201 1/ 201 l-2015) conformando un "nuevo" partido político - Unión Pro - que en líneas generales representó a los sectores de centro-derecha en el mapa político nacional. Durante esas dos gestiones locales, a nivel nacional Argentina fue gobernada por Cristina Fernández de Kirchner (2007-201 1/201 1-2015), que sucedió en la presidencia a su marido, Néstor Kirchner (2003-2007), proponiendo gobiernos que al menos en materia discursiva se alinearon a tendencias populares/ progresistas, de izquierda o centro-izquierda, con fuertes críticas al modelo económico neoliberal que ocuparon la escena política latinoamericana en estos años. Tal como señalé en otro trabajo (Infantino 2019b), del período suelen destacarse ciertos logros en materia de ampliación de derechos con fuertes posicionamientos en temas nodales en torno a derechos humanos, justicia social, redistribución de la riqueza aunque también importantes limitaciones. ${ }^{2}$ Más allá de estos logros y limitaciones, resulta importante destacar como ambas gestiones políticas se erigieron como modelos diferenciales y, en lo concreto, cómo posicionó y afectó esto a los y las artistas con los que vengo trabajando.

Específicamente en el ámbito de la cultura y sus políticas, comenzaron a surgir propuestas de políticas democrático-participativas en las que la experiencia de Brasil se erigió como modelo regional que, entre otras cuestiones, implicó un cuestionamiento ante la centralidad/exclusividad del Estado en la formulación de las políticas culturales y nuevas modalidades de pensar el vínculo Estado-sociedad. ${ }^{3}$ Aquí, los conceptos de derechos culturales y demo-

2 Suelen evaluarse como limitaciones de los gobiernos kirchneristas, por ejemplo, que no se llegaron a modificar las matrices del modelo liberal desarrollista y que si bien hubo un importante proceso de desendeudamiento, en cierta medida no se logró una gran autonomía del sistema financiero internacional. Por otra parte, aun cuando el discurso de la justicia social y la distribución de la riqueza fueron banderas del kirchnerismo recuperando los lineamientos históricos del peronismo - y debemos destacarlo, se logró cierta recuperación de condiciones de vida y hasta una suerte de movilidad social ascendente a través del incentivo del consumo y el mercado interno - no se logró afectar sustancialmente la desigualdad estructural en el país.

3 Las políticas culturales desplegadas por Brasil en estos años bajo el ministerio a cargo de Gilberto Gil en la primera presidencia de Lula da Silva (2003-2008) y su impacto regional amerita un desarrollo específico que por espacio no puedo desarrollar aquí. No obstante, señalo que los programas [continua] 
cracia cultural participativa (Chauí 2013; Calabre y Lima 2014; Vich 2014) comenzaron a ocupar un espacio central a partir de los cuales se cuestionaron los modelos de democratización/difusionismo cultural (García Canclini 1987), sosteniendo que la función del Estado no podía limitarse a democratizar el acceso a la cultura - a través de la difusión del arte y el patrimonio - sino que además se debía garantizar la participación efectiva de los propios hacedores culturales en el diseño y gestión de las políticas culturales destinadas a estos.

Más allá de la implementación efectiva o no de esta conceptualización de políticas culturales y el entrecruzamiento con tendencias en las que la visión utilitaria e instrumental de la cultura continuó primando, lo cierto es que este contexto regional instaló un fuerte discurso de reivindicación del rol del Estado como garante de derechos y promotor de demandas sociales. Así, al menos desde principios de la década de 2010 en Argentina, asistimos a un proceso en el que crecieron y se consolidaron las demandas por instrumentos legislativos - leyes de promoción/protección, creación de programas públicos, declaratorias patrimoniales, etc. - en manos de artistas independientes y trabajadores culturales referentes de diversos lenguajes que comenzaron a disputarle al Estado - nacional y local - políticas y leyes que contemplen las particularidades de sus prácticas artísticas, sus necesidades y demandas.

Resulta insoslayable mencionar a la Ley Nacional de la Música ${ }^{4}$ ya que fue una de las primeras iniciativas que abrió el camino para que otros colectivos culturales visualizaran como posibilidad la demanda por instrumentos legislativos al Estado. Como sostuve en otro trabajo (Infantino 2019a), dicho proceso de disputa por reconocimiento y garantías implicó un "modelo" para

de política pública Cultura Viva y Puntos de Cultura tuvieron un impacto regional, promoviendo movimientos de demanda hacia los Estados nacionales latinoamericanos para que garanticen un $0,1 \%$ de sus presupuestos en función de promover el desarrollo de la "cultura viva comunitaria", concepto que sirvió para representar la cultura realizada en y por las comunidades de manera independiente y autogestiva y su necesidad de apoyo estatal. Así, se conformaron redes y organizaciones artístico-políticas y se replicaron demandas por legislación y políticas públicas en distintos países latinoamericanos. Para profundizar en este tema ver: Turino (2013), Calabre y Lima (2014), Santini (2017), Infantino (2019a).

4 Tal como lo señalan diversos autores (Lamacchia 2012; Cingolani 2019) el mundo del rock y la música independiente son difícilmente abordables sin hacer referencia a la tragedia de Cromañón: el incendio de un local durante un recital de rock que tuvo como resultado la muerte de casi 200 personas en el año 2004. Luego de esta tragedia, las políticas culturales fueron reorientadas a intensificar los controles en los espacios más pequeños - donde circulaban bandas y grupos alternativos - favoreciendo la concentración del negocio de la música, las grandes productoras y los megaeventos (Morel 2018). En este contexto, muchos músicos se organizaron y comenzaron a pelear en función de garantizar derechos culturales en tanto promoción de ámbitos diversos para desarrollar sus prácticas, y en defensa de los derechos de los/las artistas y trabajadores de la música. Esta organización colectiva tuvo como correlato el diseño de una ley que promueva la música independiente junto con la creación, años más tarde, del Instituto Nacional de la Música. La Ley Nacional de la Música fue finalmente sancionada el 29 de noviembre de 2012, aunque su trabajo de elaboración tuvo una historia más larga que implicó la articulación entre músicos independientes y Estado nacional bajo la presidencia de Néstor Kirchner desde el año 2006. 
distintos colectivos artísticos. Así, bailarines/as, tangueros/as, murgueros/as, cirqueros/as, teatreros/as, gestores/as y trabajadores/as de centros culturales y artistas callejeros/as, entre otros, fueron demandando proyectos legislativos que incorporasen las especificidades de cada lenguaje/sector cultural, evidenciando necesidades y problemáticas específicas, así como transversales al campo artístico-cultural.

Si bien en el ámbito de la CABA el primer gobierno de Macri (2007-2011) había comenzado su gestión con propuestas tendientes al recorte presupuestario de programas culturales y al ordenamiento del espacio público, este clima de época a nivel nacional y regional comenzó a habilitar, también en el contexto local, la demanda por instrumentos legislativos en manos de los artistas. Así, ante la existencia de un vacío legal en torno a la figura del artista callejero que, de acuerdo a las narrativas de los artistas, venía habilitando el aumento de los niveles de violencia y persecución policial desde la asunción de Macri, los artistas callejeros porteños

"con el apoyo de organizaciones de Derechos Humanos, la Unión de Músicos Independientes (UMI) [responsable de la movilización colectiva que culminó en la sanción de la Ley Nacional de la Música], y varios legisladores porteños, iniciaron la construcción de una herramienta de regulación de su actividad. El proyecto de Ley con el fin de proteger, propiciar y fomentar la actividad artística en la Vía Pública y el espacio público [...] ingresó en la Comisión de Cultura [...] el 1. ${ }^{\circ}$ de septiembre de 2012. Nunca fue tratado" (La Izquierda Diario, 5 de julio de 2018).

En los años subsiguientes la diversidad de demandas por legislación ante los vacíos legales en la escena porteña fue habilitando la articulación entre distintos colectivos y la visualización de un camino en común que abría intersticios institucionales. Por ejemplo, el Movimiento de Espacios Culturales y Artísticos (MECA) en 2014 logró la aprobación de una ley regulatoria que permita la habilitación de los espacios culturales independientes de la ciudad. Ese mismo año surge el Frente de Artistas Ambulantes Organizados (FAAO) cuando se efectúa el traspaso de la seguridad de los subterráneos de la policía federal a la policía metropolitana, hecho que implicó el crecimiento acelerado de las denuncias por persecución y/o amenazas hacia los artistas de los subtes de Buenos Aires. Este hecho puntual traccionó la organización de varias asambleas de artistas ambulantes/callejeros de la ciudad - promovidas por los artistas que habían gestado el armado del proyecto de fomento del 2012 - y el surgimiento del FAAO, que se formalizó en asociación civil en 2015, gracias a la asesoría de Abogados Culturales, otra de las organizaciones que se erigieron en referentes de la disputa ante los vacíos legales en materia de habilitaciones/permisos para desarrollar arte en la ciudad. 
Podría mencionar varios ejemplos más pero destaco estos para dar cuenta del modo en el que se fue gestando una disputa político-cultural colectiva y transversal que fomentó la articulación de distintos grupos/organizaciones artísticos de la ciudad en función de demandar legislación no punitiva - que dispute las clausuras, inhabilitaciones, persecuciones $-\mathrm{y}$ promotora de la actividad independiente como un derecho. Por ejemplo, Alejandro Cabrera Britos, quién fue creador y Presidente del FAAO, lo relata en estas palabras: "gracias a la aprobación de la Ley de Centros Culturales en diciembre de 2014, 'se dejó una puerta abierta para llegar a un montón de legisladores y se allanó el camino para que nosotros [los artistas callejeros] elaboremos una ley que nos ampare" (nota periodística, Emergentes, 26 de mayo de 2016. Disponible en < https://medium.com/@EMERGENTE/faao-lo-que-propone-el-pro-es-un-desaliento-para-el-artista-callejero-9aca832 l e29 >.

Los artistas del FAAO suelen relatar como a partir de estos años comenzaron a desplegar estrategias para presentar sus proyectos a legisladores de distintos partidos políticos. Recuerdo una de mis primeras visitas a la Legislatura junto a Alejandro cuando nos iba a presentar a una asesora de una diputada para comentarle acerca de los proyectos que estábamos desarrollando junto a Circo Abierto, otra de las organizaciones que venían actuando en esta línea de demanda por instrumentos legislativos en el campo del circo. Mientras recorríamos los pasillos de la Legislatura, un gran edificio histórico donde trabajan legisladores y asesores de la CABA, Alejandro me relataba las maneras en las que habían presentado diversos proyectos para la protección de los/as artistas callejeros/as: "Nosotros entrábamos para ver a algún diputado que nos recibía, nos controlaban el documento y después de la reunión pactada no nos íbamos. Empezábamos a recorrer despachos, golpear las puertas, dejar nuestro proyecto, explicarlo, tomar el contacto" [registro de campo, abril de 2018]. De esta manera, los enlaces y articulaciones con referentes del campo político crecían y se afianzaban mientras que los/as artistas aprendían el lenguaje y los modos de funcionamiento de este campo.

Ahora bien, los movimientos que se venían gestando en materia de disputa político cultural en la escena porteña, adquirieron ciertas especificidades para fines de 2015 en vínculo a un nuevo escenario político en el país. El 10 de diciembre de 2015, el entonces jefe de gobierno porteño Mauricio Macri asumió la presidencia nacional, para la que triunfó en las elecciones democráticas a través de una alianza con sectores del partido radical denominada "Cambiemos". El "cambio", propuesto desde la plataforma gubernamental, incluía ciertos cuestionamientos al gobierno saliente de Cristina Fernández de Kirchner en diversas áreas, entre ellas en materia de efectividad/eficiencia en el manejo del Estado. Paralelamente, en la CABA volvió a triunfar el partido gobernante (Unión Pro-Cambiemos) y desde diciembre de 2015 la jefatura de gobierno está presidida por Horacio Rodríguez Larreta. 
Específicamente en el área de cultura, el nuevo gobierno local nombró como ministro de Cultura a Darío Lopérfido, funcionario que tras meses de asumir sus funciones cuestionó el número de 30.000 detenidos-desaparecidos durante la última dictadura nacional (1976-1983). Este hecho puntual generó un movimiento de rechazo que nucleó no solo a los diversos organismos de Derechos Humanos (DDHH) sino también a gran parte del movimiento cultural porteño que se oponía a que un funcionario que pusiera en duda la cifra de desaparecidos en la última dictadura militar - cuestionando al mismo tiempo la credibilidad de los organismos de DDHH - pueda estar al frente de la cartera de cultura de la ciudad. Finalmente, en julio de 2016 el funcionario renunció a su cargo. Lo sustituyó Angel Malher que estuvo al frente del ministerio hasta fines de 2017 cuando asumió el actual ministro Enrique Avogadro (2017-2019).

A raíz de las protestas contra Lopérfido (imagen 1), que abrieron el calendario político del año 2016 , se fue conformando una línea de disputa política alrededor del área cultural que unió diversos referentes del campo cultural con militantes políticos - mayormente vinculados al kirchnerismo o bien opositores al partido gobernante - y artistas independientes. Comenzó así a aparecer una columna de cultura en las movilizaciones que saturaron el mapa político durante el primer año de mandato de Macri y empezó a gestarse, por ejemplo, Cultura Unida como ámbito asambleario que fue generando una "organización de agrupaciones destinada a defender y promover la cultura" (Facebook de Cultura Unida, < https://www.facebook.com/la.cultura. unida/ $>$ ).

Todas estas articulaciones entre organizaciones y colectivos culturales fueron entrelazando luchas que en cierta medida colocaron como tema de agenda político-estatal algunas cuestiones centrales: la obligación del Estado de garantizar derechos y políticas culturales democráticas, en las que sus protagonistas participen activamente.
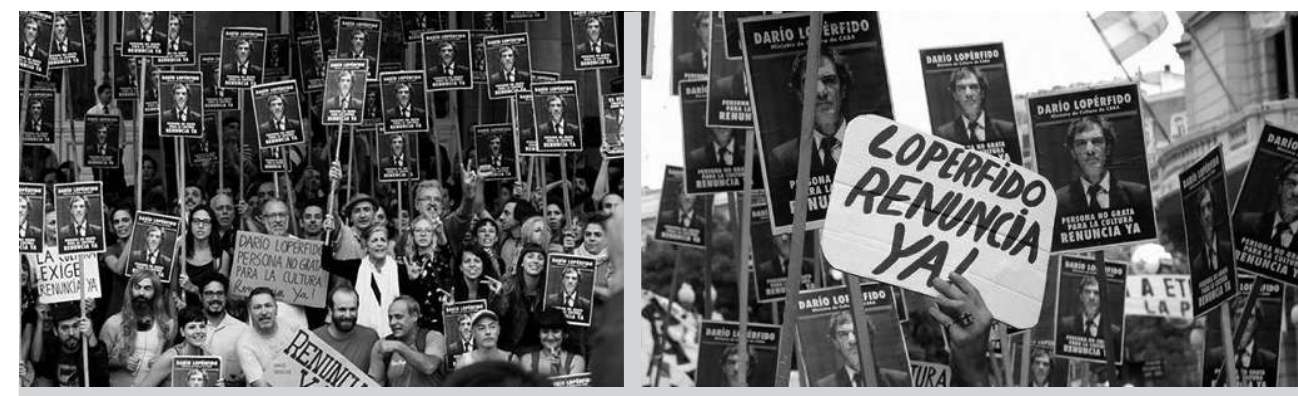

Imagen 1 - Protesta exigiendo la renuncia del titular del Ministerio de Cultura porteño. Fuente: <https://www.eldiariodebuenosaires.com >, <https://www.eldiariodebuenosaires.com/2016/0 6/15/los-organismos-de-ddhh-contra-dario-loperfido-es-el-primer-mojon-de-una-avanzada-negacionista/ $>$. 


\section{LA REFORMA DEL CÓDIGO CONTRAVENCIONAL PORTEÑO. ESTRATEGIAS Y RESIGNIFICACIONES EN LA DISPUTA POLÍTICO-CULTURAL}

Este es el contexto político en el que el gobierno de la CABA presentó el proyecto de ley para reformar el código contravencional porteño (1664/J/18) en junio de 2018, proponiendo una regulación punitivista al desarrollo de actividades en el espacio urbano. Entre las sanciones al acoso callejero o a la limpieza de vidrios en la vía pública y otras actividades que se pretendían reglar como contravenciones, se incluía la formulación del artículo 85 que, a través de la figura de "ruidos molestos", afectaba a los/as artistas de la ciudad que trabajan en el espacio callejero. Unos días después de anunciado el proyecto de reforma del código contravencional, el FAAO comunicaba lo siguiente:

\section{“ARTISTAS CALLEJEROS: URGENTE!!!}

Una vez más, esta gestión de gobierno expone su desprecio por la cultura independiente. Los artistas callejeros estamos en PELIGRo!!! Si bien unos años atrás logramos paralizar el Proyecto de Ley 2538/15, el Macrismo vuelve a atacar a nuestro sector mediante un nuevo Proyecto de Ley mucho más dañino y perjudicial que el 2538/15. ES NECESARIO QUE COMPRENDAMOS LA GRAVEDAD Y LA SERIEDAD DE ESTE NUEVO EMBATE. El Proyecto de Ley 2538/15 no llegó a tratarse ni siquiera en comisión. Hicimos mucha fuerza en la calle y logramos frenarlo. Este nuevo Proyecto de Ley (1664/J/18) YA ESTA SIENDO TRATADO EN LA COMISIÓN DE JUSTICIA y por otra parte, la idea es que ingrese al recinto para ser votado favorablemente lo antes posible. Recordemos que el Macrismo es mayoría en la Legislatura, con lo cual pueden sacarlo rápidamente. Algunos de los puntos más perjudiciales de este Proyecto de Ley:

- Arresto de 1 a 5 días.

- Multas de 400\$ a 2000\$.

- Denuncias anónimas, lo que facilita las denuncias falsas ya que no hay forma de comprobarlas siendo anónimas.

- Incautación por parte de la policía de nuestras herramientas de trabajo, instrumentos musicales, juguetes de malabares, etc. [...]

Compartan y difundan esta publicación compañerxs!!!

DEFENDAMOS LA CULTURA INDEPENDIENTE!!! EL ARTE CALLEJERO NO ES DELITo!!! F.A.A.O. Frente de Artistas Ambulantes Organizados." (Publicación de Facebook de FAAO, 12 de junio de 2018. Disponible en < https:// www.facebook.com/groups/Frentedeartistasambulantes/ >).

La publicación citada comenzó a circular por las redes sociales y tuvo amplio eco en la organización colectiva que se venía gestando en años anteriores. Así, 
la puerta de la Legislatura porteña ubicada en Perú 160 (microcentro porteño) se convirtió en cita obligada para artistas callejeros en sucesivos martes - día en el que se trataba el proyecto de ley - en los que se realizaron protestas ampliamente concurridas, que incluyeron performances individuales y/o grupales, intervenciones en el espacio público con pancartas y producciones gráficas con la leyenda "El arte callejero no es delito", una gran difusión en redes sociales, el apoyo de referentes mediáticos del campo artístico y la articulación entre colectivos e instituciones del campo cultural local (imagen 2).

Pero la acción de estos colectivos artísticos no se limitó a estas estrategias, sino que se entrelazó con la constancia en la articulación-negociación política con los propios legisladores y funcionarios públicos. Tal como analicé en el apartado anterior, muchos de estos colectivos ya venían articulando entre ellos y con referentes políticos, por lo cual conocían "desde adentro" los mecanismos de debate parlamentario, sabían cómo participar transmitiendo sus demandas y cuáles eran los momentos decisivos y los estratégicos para actuar.

Durante algunas de las sesiones en las que se trató la reforma, la masividad de la protesta y su difusión mediática resultó de gran utilidad para presionar la modificación del proyecto. De hecho, luego de las primeras protestas el ministro de Cultura porteño, Enrique Avogadro, convocó a las diferentes
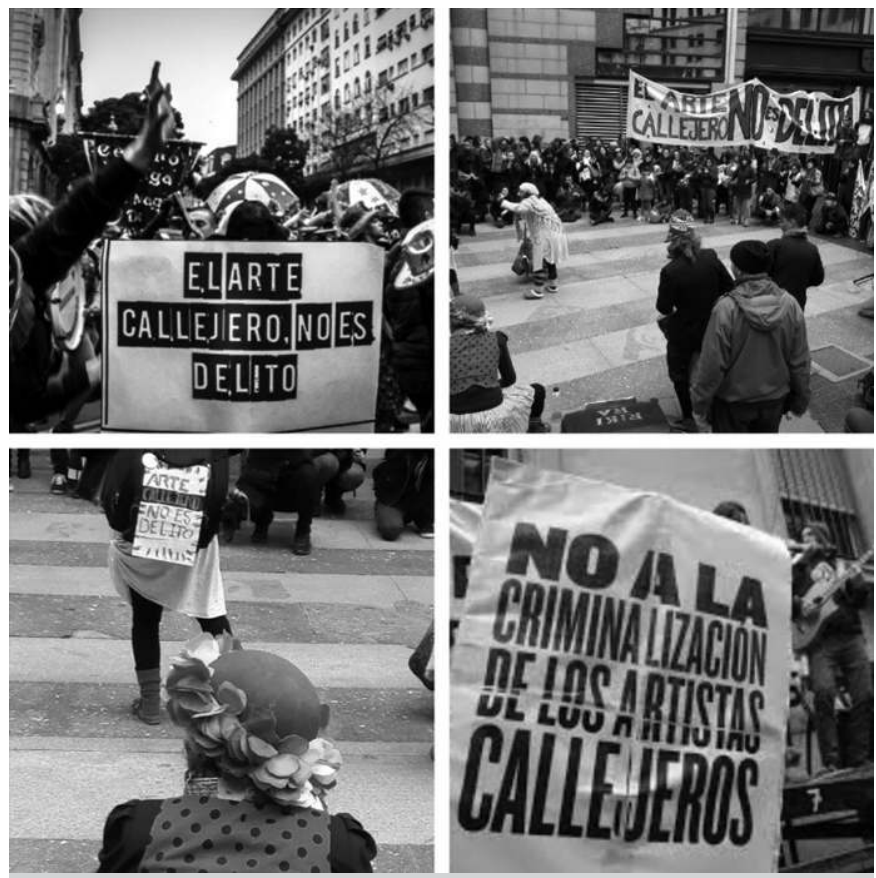

Imagen 2 - Fotografías en diversas protestas ante la reforma del código contravencional porteño. Junio-agosto de 2018 , CABA. Fuente: archivo personal. 
organizaciones de la cultura que venían protagonizando los reclamos: Cámara de Clubes de Música en Vivo (Clumvi); Cultura Unida; Movimiento de Espacios Culturales y Artísticos (MECA); Sociedad Argentina de Músicos (Sadem); Circo Abierto; Frente de Artistas Ambulantes Organizados (FAAO); Espacios Escénicos Autónomos (Escena); Trabajadorxs Feministas de Espacios Culturales; Mujeres, Lesbianas, Travestis y Trans (Fiera); y Abogados Culturales. En dicha reunión, el ministro se comprometió a proponer la incorporación de modificaciones al proyecto de ley que se estaba tratando en la Comisión de Justicia con el fin de preservar a los artistas y al arte callejero porteño de la reglamentación restrictiva. En palabras del propio ministro de Cultura porteño que aparecieron en medios de comunicación luego de la reunión mencionada:

"Buenos Aires es una de las capitales culturales del mundo gracias al dinamismo de todos los que día a día desarrollan actividades artísticas y culturales. Seguimos trabajando para que la cultura independiente tenga más protagonismo y presencia en todos los barrios de nuestra Ciudad. Estamos a favor de que haya cada vez más expresiones artísticas: en los teatros, en los centros culturales, en las salas de música, en las galerías, en los clubes y, por supuesto, en el espacio público. Todas ellas hacen de Buenos Aires una Ciudad única de la que podemos sentirnos orgullosos" (La Nación, 4 de julio de 2018. Disponible en < https://www.lanacion.com.ar/cultura/artista s-callejeros-se-reunieron-con-el-ministro-avogadro-por-un-polemico-proyect o-de-ley-nid2 $148768>$ ).

Alejandro Cabrera Britos lo comentaba de este modo en un posteo de Facebook del FAAO:

“Desde junio de este año la Legislatura Porteña se dedicó desde las comisiones de Justicia y de Asuntos Constitucionales, a tratar el proyecto 1664J18 [...]. Durante una cantidad de martes participamos de reuniones de comisión de asesores y de legisladorxs, quienes venían tratando el proyecto. En simultáneo comenzamos a dialogar con el ministro de cultura de la ciudad, Enrique Avogadro, quien ayudó a articular con diferentes sectores institucionales, y frente a nuestro pedido, y el de otros colectivos, sindicatos y espacios, para modificar el contenido del artículo 85 del mencionado proyecto, para que exprese, que la actividad artística en el espacio público no constituya contravención, como la actividad artística conocida con la modalidad de 'a la gorra' [...] hasta ahora en lo verbal, la actividad artística en el espacio público quedaría exceptuada de ser considerada como contravención" (Alejandro Cabrera Britos, Publicación de Facebook del FAAO, 11 de diciembre de 2018. Disponible en < https:/www.facebook.com/groups/ Frentedeartistasambulantes/ $>$ ). 
A partir del compromiso del ministro de Cultura porteño por desafectar al arte callejero de la reforma contravencional en julio de 2018, los/as artistas callejeros/as se mantuvieron en estado de alerta, continuaron movilizando para presionar ese compromiso y para solidarizarse con otros actores sociales a los que la reforma del código seguía afectando. Además de los colectivos ya mencionados, fue importante la presencia de otras organizaciones de artistas tanto formales como informales: Músicos organizados; Trabajadores de la Cultura Ambulante (TCA); Payasos con Memoria; Ejercito de Payases; Cirqueres organizades; Murgueros y Murgueras; estudiantes/docentes y trabajadores de diversos espacios institucionales como la Escuela Metropolitana de Arte Dramática (que cuenta con un Curso de Formación del Actor/Actriz para la Actuación en Espacios Abiertos) o la Universidad Nacional de las Artes (UNA); entre otros.

Así, además de continuar desplegando sus protestas frente a la legislatura porteña con performances artísticas, reforzaron la lucha por disputar la valoración del arte callejero como manifestación cultural de la ciudad. A la difusión de la problemática en redes sociales y medios de comunicación se sumaron estrategias como la de informar a los espectadores en las performances callejeras acerca del proyecto oficial y la criminalización para el arte callejero que implicaría en caso de aprobarse. Asimismo, emergió nuevamente la necesidad de demandar una ley que reconozca y proteja al arte callejero y a sus trabajadores. En octubre de 2018 se reflotó uno de los proyectos que ya había sido trabajado desde el FAAO, otros colectivos y el bloque kirchnerista - Frente para la Victoria $(\mathrm{FpV})$, opositor al partido gobernante $-\mathrm{y}$ presentado en años anteriores que proponía declarar como:

"Bien Integrante del Patrimonio Cultural de la ciudad en los términos fijados en el inciso J del artículo 4 de la Ley 1227, 'Expresiones y Manifestaciones Intangibles' a las actividades realizadas por los artistas ambulantes y/o itinerantes (músicos/as, bailarines/as, cirqueros/as, actores y actrices, coros, elencos teatrales, mimos, titiriteros/as, estatuas vivientes, payasos/as, artistas plásticos/as y similares) en el ámbito de la Ciudad de Buenos Aires" [Proyecto de Ley presentado por Lorena Pokoik (FpV), Legislatura de la Ciudad Autónoma de Buenos Aires, exp. N. ${ }^{\circ} 777 /$ D2018].

Aquí la intención de declarar al arte callejero como patrimonio cultural debe ser leída también en términos estratégicos. Si bien la figura de patrimonio cultural intangible circula entre los artistas de la ciudad hace años - ya que diversas manifestaciones culturales han sido reconocidas en estos términos -, en este contexto, de acuerdo a las apreciaciones tanto de artistas como de asesores y legisladores que recabé en el trabajo de campo, las posibilidades que brindaría la figura del patrimonio resultan estratégicas por dos motivos. Por 
un lado, ante la dificultad o imposibilidad de generar políticas institucionales que mediante erogación presupuestaria y creación de nuevas estructuras desplieguen acciones concretas para la promoción, difusión y fortalecimiento de determinada práctica cultural, la declaratoria patrimonial se visualiza como más viable en un contexto político adverso, de ajuste y austeridad en la acción estatal. Por otro lado, declarar al arte callejero como patrimonio cultural intangible de la ciudad, habilitaría cierta protección institucional que podría redundar en la no persecución de los artistas.

De hecho, más allá de que la mayoría de los/as artistas callejeros/as con los/ as que interactué en el trabajo de campo defienden lo que hacen como un arte que debería ser reconocido, promovido y valorizado, la demanda en torno a la figura del patrimonio se presentó en este contexto conjugando la posibilidad de puesta en valor/jerarquización del arte callejero junto a la urgencia por contar con instrumentos legales de protección. En ese sentido hablo de uso estratégico.

En efecto, ese uso estratégico del patrimonio se visualiza en el modo en el que en esos meses fueron surgiendo proyectos legislativos - declaratorias patrimoniales y/o de interés cultural para los/as artistas callejeros/as - articulados entre artistas y legisladores de distintos lugares del país. Así, con especificidades, pero el mismo espíritu que busca descriminalizar y fomentar, se presentaron, aprobaron o se encuentran en tratamiento proyectos similares en la Provincia de Buenos Aires, en la ciudad de La Plata, en el Partido de la Costa, y, tal como analicé, en la propia ciudad de Buenos Aires. Asimismo, un proyecto modelo de declaratoria patrimonial se comparte como insumo en redes sociales o en grupos cerrados de WhatsApp conformados por artistas callejeros/as, con el fin de que sirva para que artistas en distintos puntos del país puedan disputar reconocimiento, fomento y descriminalización de sus prácticas. Esta estrategia política de replicar reclamos y compartir instrumentos se encuentra claramente vinculada al uso de las nuevas tecnologías y al modo en que las mismas habilitan la conformación de redes y la socialización de la información, eje que sería pertinente analizar en profundidad pero que trasciende el eje de este trabajo.

Al tiempo que en CABA se continuaba tratando la reforma del código contravencional con el compromiso del ministro de Cultura de exceptuar explícitamente a los artistas callejeros a la gorra, los/as propios/as artistas de la ciudad continuaban generando redes y proyectos para ampliar la mera desafectación del arte callejero como contravención. Así, se fue gestando un "colectivo de colectivos", tal como lo denominaron los/as artistas, que continuó reuniéndose, planeando acciones y discutiendo proyectos de legislación para la promoción del arte callejero en la ciudad.

Finalmente, la reforma del código contravencional porteño que fue aprobada el 13 de diciembre de 2018 excluyó expresamente al arte callejero a la 
gorra alegando que este tipo de expresión artística no implica contravención ni "ruidos molestos". Cabe resaltar que este logro evidenció la diversidad de posturas y líneas (contradictorias) en el accionar del GCBA (Gobierno de la Ciudad de Buenos Aires) entre diversas agencias públicas. Por un lado, la reforma impulsada desde la Comisión de Justicia buscaba un ordenamiento del uso del espacio público y en cierta medida respondía a una demanda de un sector de la sociedad que aboga por un espacio público sin conflictos, reglado, sin informalidad ni marginalidad; marginalidad con la que a su vez es representado el arte callejero. Por otro lado, desde la propia cartera de cultura del mismo gobierno, la actividad artística callejera es vista como una práctica que hace a "Buenos Aires $[\ldots]$ una de las capitales culturales del mundo", única por su dinamismo cultural y por su "cultura independiente", tal como citaba con anterioridad en palabras del ministro de Cultura porteño.

Si bien no podemos dejar de mencionar que este logro de los artistas callejeros se debió claramente a la potencia de la movilización colectiva y a la disputa/negociación política que conllevó, también el proceso pone en evidencia que el Estado no es un bloque monolítico y homogéneo que funciona de forma ordenada y coordinada, sino que más bien se presenta como un entramado de relaciones, vínculos e intereses diversos. Desde una perspectiva deudora de las propuestas impulsadas desde la antropología del Estado y la(s) política(s) (Shore 2010, entre otros) adhiero a la necesidad de cuestionar las representaciones del Estado como una entidad o un conjunto de instituciones homogéneas y a las políticas públicas como consecuencia de procesos lineales y mecánicos que vienen de arriba hacia abajo. Más bien, la acción estatal suele implicar procesos no lineales, complejos, desordenados, muchas veces contradictorios, que asimismo conllevan resistencia y negociación.

Considero que el análisis propuesto hasta aquí nos coloca ante la disputa acerca de los sentidos desiguales con los que se connota la cultura, las artes y las políticas culturales. Evidencié a partir de los aportes etnográficos, como los/as artistas callejeros/as junto a diversos actores políticos - agentes estatales, legisladores, referentes de movimientos sociales y culturales - actuaron en esta arena de disputas, abogando por el reconocimiento de las propias prácticas artísticas e instalando a dichas prácticas como tema de agenda estatal; agenda que muchas veces evidencia contradicciones, pujas y complejidades. A través del caso analizado mostré cómo los/as artistas callejeros/as, junto a otros actores sociales y políticos, presionaron legislación/políticas públicas y fueron encontrando intersticios y estrategias para lograr que el arte callejero no fuera legislado como delito.

En el último apartado de este texto analizaré específicamente la organización colectiva entre los/as artistas que implicó el proceso desarrollado hasta aquí. Propongo estudiar esta colectividad como estrategia política que se movió entre consensos y disensos y que instaló, entre otras cuestiones, la necesidad 
de repensar las formas de significar lo político/crítico en el arte en relación a ciertas nociones centrales como la de independencia.

\section{LO COLECTIVO, LO POLÍtico Y LA POLITIZACIÓN DEL ARTE}

Josefina Cingolani, en su tesis doctoral en la que trabajó en torno a la conformación del circuito de rock en la ciudad de La Plata (Cingolani 2019), propone una interesante reflexión en torno a cómo fue construyendo las categorías que le permitieron desarrollar el análisis. La autora argumenta que en un principio intentaba ver al circuito de rock platense desde las disputas entabladas al interior del campo en términos de capitales y lógicas pensadas desde la exclusión, los conflictos, la imposición (Bourdieu 1995), pero que a lo largo del trabajo de investigación encontró además de ciertas disputas - por ejemplo en torno a qué estilos representarían más adecuadamente la tradición rockera de la ciudad - instancias de negociación, encuentro, colaboración (Becker 2008). La autora propone entonces que más que hablar de disputas y consensos como dos modos de vinculación antagónicos y distantes entre los actores, era preciso hablar de vínculos circunstanciales, móviles y cambiantes. Cingolani analiza por ejemplo como en función de luchar contra las clausuras que acontecieron en diversos espacios del circuito de rock platense en los últimos años, los artistas de distintos estilos rockeros de la ciudad apelaron a la noción de comunidad y a la colaboración para enfrentar el carácter punitivo de ciertas agencias de control estatal local.

En esta misma línea, a lo largo de mis años de trabajo con la formación cultural circense relevé intensas disputas en torno a la definición de las maneras legítimas de hacer circo que, principalmente, se traducían en dicotomías como popular/refinado, contemporáneo/tradicional, comprometido-politizado/mercantilizado-elitizado. Estudié cómo estas divergencias ponían de relieve posturas artísticas, estéticas, políticas e ideológicas diferenciales, así como disputas por recursos tanto económicos como simbólicos (Infantino 2014). Ahora bien, cuando los y las artistas circenses se organizaron colectivamente para demandar una ley nacional de Circo, si bien estas disputas no se diluyeron, el énfasis se colocó "en trascenderlas apelando a un sentido colectivo, de comunidad, que incorpore las diversidades de estilos, historias, procedencias, trayectorias en una construcción de identidad común" (Infantino 2019b: 292) y en un reclamo político que redunde en posibles beneficios para todos/as los/as artistas circenses.

Considero que la posibilidad de articular ambos lentes conceptuales que tejen movimientos entre disputas y consensos al interior de las formaciones culturales puede aportar al análisis del caso de los/as artistas callejeros/as abordado aquí. La organización colectiva en función de demandar políticas y legislación al Estado no puede ser vista como un proceso sin conflictos ya 
que llevaría a pensar que lo colectivo/comunitario es armonioso per se. Más bien propongo comprender como la disputa político-cultural fue instalando la necesidad de trascender los conflictos internos en torno a las modalidades diferenciales de comprender la práctica artística, para lograr mayores derechos. De hecho, uno de los ejes de conflictos puede vincularse a las diferentes modalidades de concebir la noción de independencia frente al Estado que se fueron poniendo en escena en el caso estudiado.

La idea de independencia en las narrativas de los artistas callejeros suele aparecer asociada a conceptos como autogestión, libertad, resistencia, transgresión, crítica, compromiso. Estudié como específicamente para el caso de los artistas callejeros circenses al menos desde los años 1990 las nociones de independencia/autogestión se erigieron como banderas de disputa y resistencia contracultural (Infantino 2014). ${ }^{5}$ En un contexto de afianzamiento del modelo neoliberal en el que la inversión a futuro basada en el esfuerzo personal, el estudio, el sacrificio - como pilares que habían caracterizado históricamente el imaginario de clase media - ya no garantizaban ni la movilidad social ascendente ni la estabilidad laboral, el trabajo artístico callejero emergió como opción viable. Opción válida no solo para garantizar la supervivencia económica de muchos jóvenes que eran desplazados del mercado de trabajo formal, sino también como alternativa para imaginar otras formas de habitar/resistir ese mundo neoliberal.

Aquí, la representación del arte callejero como modo alternativo de vida y trabajo - no normativo, libre, informal, colectivo, transgresor - se erigió en modalidad de crítica y cuestionamiento político. Ocupar el espacio público desde el arte callejero era concebido como una estrategia para democratizar el acceso y circulación del arte, era un modo de oponerse frente a las jerarquizaciones del campo artístico reivindicando un arte popular que disputaba la privatización del espacio urbano o la elitización y mercantilización de la cultura propia de la época (Infantino 2014). Además, era una estrategia para garantizar la supervivencia económica de un modo alternativo (no formal), que habilitaba vincular la práctica laboral con un posicionamiento artístico-ideológico asociado a la transgresión, la independencia y la crítica contracultural.

Ahora bien, estas nociones también estuvieron acompañadas de la construcción del Estado como un "otro" en tanto aparato burocrático y de control frente al que había que resistir y al que en líneas generales no se le demandaban

5 Utilizo este concepto en tanto categoría nativa y no como una categoría de análisis. En efecto, debemos pensar críticamente la idea de contracultura en tanto ha permitido abordar las prácticas culturales críticas desde una visión idealizada y romantizada, frecuentemente desgajada de las condiciones estructurales en las que las prácticas se ubican. Tal como desarrollaré más adelante, muchas veces la independencia como categoría nativa de disputa contracultural conlleva procesos de naturalización de la precariedad y marginalidad en las condiciones de producción y reproducción artística. 
políticas, derechos o recursos. Desde esta postura "anti-oficial" se connotaba también la noción de independencia. El caso que analicé en este trabajo pone de manifiesto cómo se va instalando otra capa de sentido para significar la noción de independencia. Alejandro del FAAO lo planteaba de esta manera:

"A los artistas callejeros de la Ciudad de Buenos Aires se los viene persiguiendo desde hace nueve años, es decir, desde que el PRO llegó al poder en forma democrática [en referencia al año 2007 cuando Macri asumió como jefe de gobierno porteño]. Se nos persigue porque lo que estamos proponiendo es una formalidad no convencional, queremos que el Estado nos proteja [...] 'queremos que se entienda que la autogestión es una posibilidad, que el arte independiente puede decir muchas cosas desde otro lugar' " (nota periodística, Emergentes, 26 de mayo de 2016. Disponible en < https:// medium.com/@EMERGENTE/faao-lo-que-propone-el-pro-es-un-desalientopara-el-artista-callejero-9aca832 le29 >).

La demanda de "protección" y cierta "formalización (no convencional)" desde la organización colectiva de los/as artistas callejeros/as en articulación-negociación con el Estado nos coloca ante estas resignificaciones. Si otrora la disputa político cultural y lo político de la práctica artística callejera se connotaron con nociones como ocupación del espacio urbano, independencia/autogestión, resistencia frente al Estado y a las instituciones públicas, aquí se presenta otra modalidad de disputa u otra capa de sentido, en tanto las versiones anteriores no son suplantadas; más bien hay una adición de nuevas formas de significar.

Esta nueva capa de sentido podría ser conceptualizada como una búsqueda por "radicalizar la democratización de las instituciones", retomando los términos de Chantal Mouffe (2014). La politóloga belga, desde una crítica a posturas que proponen el éxodo de las instituciones como estrategia de lucha contrahegemónica, plantea la necesidad de actuar desde "una multiplicidad de acciones contrahegemónicas con el objetivo de lograr una transformación profunda de las instituciones existentes y no su deserción" (Mouffe 2014: 19). Si bien la propuesta teórica de Mouffe en este punto resulta programática, es decir, un llamado a disputar la hegemonía neoliberal a partir de la ocupación y democratización radical de las instituciones, retomo aquí su planteo para analizar esta nueva capa de sentido en torno a la independencia que estoy proponiendo para el caso específico estudiado.

Tal como planteé con anterioridad, esto debe ser vinculado al contexto político más amplio que involucró tanto una reconceptualización del rol del Estado como garante de derechos y una resignificación del rol de los artistas en función de demandar la democratización de las instituciones culturales, en definitiva, otra modalidad de ejercer la disputa político-cultural. Por consiguiente, 
la posibilidad de demandarle al Estado reconocimiento, participación y garantías - o sea, instituciones y políticas más democráticas y participativas - se presentó en este contexto como una nueva estrategia que implicó también un replanteo frente a las posturas más libertarias o anti-sistema que habían caracterizado mayoritariamente a los/as artistas callejeros/as.

Particularmente, este replanteo implicó destacar la precariedad de la estrategia anti-sistema en relación a las limitaciones que enfrenta ante el poder del Estado, distinguiendo la idea de ocupar espacios y la de legitimar derechos. Un artista circense lo planteaba en estos términos: "Me parece que está bueno retomar la experiencia de cómo legitimar los derechos. [Por ejemplo] con los semáforos [en referencia a uno de los espacios públicos en los que los/las artistas circenses trabajan desde mediados de los 90], bueno, trabajo en el semáforo, gano unos mangos [suma pequeña de dinero] y creo que estoy legitimando el derecho a trabajar en la calle, voy a la plaza, hago una función... y después te sacan a patadas" [artista de Circo Abierto, Festival Payasadas, Rosario, 2017].

La narrativa citada pone en escena lo que vengo analizando. En los años 90 y principios de los 2000 la potencialidad política de la práctica artística callejera se vinculaba a la acción concreta de ocupar el espacio público con arte desde la práctica independiente y resistente frente a las instituciones, pero dicha práctica conllevó la naturalización de condiciones extremadamente precarias de trabajo artístico-callejero. En efecto, tal como lo evidencian ciertas investigaciones recientes del ámbito nacional (Sáez 2016; del Mármol, Magri y Sáez 2017; del Mármol 2020), la persistencia de representaciones dicotómicas entre arte y trabajo junto al alto valor otorgado a la autonomía/independencia, se convierten en elementos centrales en la precarización y auto-precarización del trabajo artístico. Aquí, una serie de movimientos en el propio campo artístico - por ejemplo, entre los/as bailarines/as demandando una ley nacional de danza estudiada por Sáez (2016) - que apuntan a la reivindicación de los artistas como trabajadores demandando marcos legales que los amparen, les garanticen derechos laborales básicos y propicien mejores condiciones para el desarrollo de su actividad y el sostén de sus vidas, vienen tensionando esas históricas nociones de independencia que describimos con anterioridad.

En nuestro caso, la estrategia de demandar legislación promotora y no punitiva que reconozca a las prácticas artísticas callejeras como cultura/patrimonio de la ciudad y a sus hacedores como trabajadores culturales también se erige como un campo para luchar contra la precarización de las condiciones de trabajo y de vida de los/as artistas. Asimismo, la organización colectiva para luchar por derechos y por políticas representativas y participativas se presentó como otra alternativa para fortalecer la disputa político-cultural.

Decía que las disputas o consensos entre los actores no pueden ser vistas como modos de vinculación antagónicos y distantes, sino más bien circunstanciales, móviles y cambiantes. En efecto, esta nueva connotación alrededor de 
la noción de independencia no emerge sin conflictos. Durante el trabajo de campo presencié diversas discusiones en torno a estas estrategias diferenciales, en las que los artistas con los que trabajé intentaban "concientizar políticamente” a los más jóvenes - y aquí hay un eje generacional muy interesante que abre una línea para indagar en futuros trabajos - acerca de la necesidad de luchar colectivamente por derechos frente a la precarización de las condiciones de trabajo artístico, de "hacer política, porque si la política no la hacemos nosotros, no la va a hacer nadie por nosotros" [palabras de un artista integrante de Circo Abierto, diciembre de 2015].

Esta línea se presentó como eje del trabajo político y militante de diversos referentes, entre los que debo destacar a Alejandro Cabrera Britos del

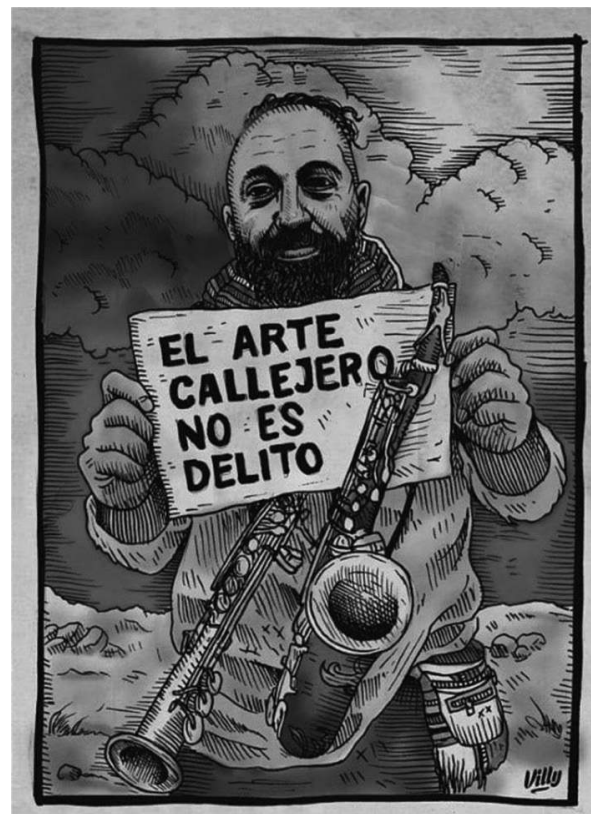

Imagen 3 - Producción gráfica en homenaje a Alejandro Cabrera Britos. Fuente: dibujo: Villy.

FAAO. Alejandro, saxofonista y músico callejero, durante años encaró un trabajo incesante en la búsqueda de concientizar acerca de los derechos de los/ as artistas, acerca de la necesidad de presionar legislaciones que promuevan y no criminalicen del arte callejero. Un llamado a hacer política, a demandar reconocimiento y derechos desde el convencimiento de luchar por la libertad y la igualdad, por el otro y colectivamente. Alejandro falleció trágicamente en un accidente automovilístico en junio de 2019. Si bien dejó un gran vacío y dolor, también dejó un gran legado que desde el FAAO se expresó en una frase como la que cito a continuación, difundida en las redes sociales luego de realizado un acto homenaje denominado "Callejerazo":

"El Callejerazo fue una experiencia humana y colectiva de una profunda belleza poética. Ale estuvo ahí. Uno de los tantos regalos que nos dejó, fue la hermandad que nos atravesó a todos y que surge de anteponer la mirada colectiva a la mirada individual. Una enorme y preciosa colección de luchadores de todos los colores y estilos defendiendo nuestros derechos como él nos enseñó, en la calle, que fue, es y será nuestra, siempre. [...] Porque una vez más, idejamos en claro que la cultura es un derecho! Porque la cultura popular no se prohíbe. iPorque recordamos y revivimos su grito, el arte callejero no es delito!" (publicación Facebook FAAO, 26 de junio de 2019. 
Disponible en <https://www.facebook.com/groups/Frentedeartistasambulan tes/ $>$ ).

Más allá de este reconocimiento al modo en que Alejandro junto a tantos/as otros y otras luchó por politizar, por generar disputas transversales y colectivas y por disputar la democratización de las políticas relativas al sector cultural, cabe destacar que si bien en el proceso de disputa frente a la reforma del código contravencional las maneras diferenciales de pensar el vínculo artistas-Estado no se diluyeron, sí se llegaron a consensos, entre ellos la necesidad de involucrarse y de negociar/presionar colectivamente legislación no punitiva y promotora al Estado local. Consensos que claramente pueden ser considerados como circunstanciales/estratégicos y que habrá que continuar analizando en su desarrollo.

\section{REFLEXIONES FINALES}

Desde los inicios de mi trayectoria de investigación, me interesó analizar las dinámicas desde las cuales se practican, se apropian/resignifican y "se usan" las artes. Encontré en estos procesos intersticios interesantes para estudiar los sentidos diversos que esos "usos del arte" conllevan, en tanto espacio de resignificación estética/estilística, como herramienta de disputa política por reconocimiento, en tanto ámbito para pelear por alternativas de vida y de trabajo o como instrumento de intervención social para luchar por la transformación de diversas injusticias que atraviesan a nuestras desiguales sociedades.

En este trabajo me interesó específicamente abordar ciertos "usos políticos" del arte, o más bien, un proceso de politización cultural que implicó una resignificación en los modos de conceptualizar las potencialidades políticas del arte callejero. Analicé cómo este proceso implicó una expansión de sentidos alrededor del concepto de independencia: de resistir a las instituciones estatales y "ocupar" los espacios callejeros - frecuentemente desde un discurso libertario, antisistema pero también desde una práctica muchas veces individual y precarizada - a intentar democratizar las instituciones. Esto, desde una disputa colectiva para lograr la participación efectiva en la formulación de legislación y políticas que reconozcan y habiliten la práctica artística callejera como un derecho.

Si consideramos junto a Richard (2011) que lo político y lo crítico en el arte se definen en acto y en situación, o sea, son contextuales y coyunturales, podemos entonces pensar que dicha politicidad no será la misma en distintos contextos tanto territoriales como de época. Los estudios sociales y antropológicos del arte contemporáneos proponen la necesidad de repensar las formas en las que se han abordado las potencialidades político-críticas en el arte para trascender reduccionismos - frecuentemente vinculados con una 
versión contenidista que atribuye dicha potencialidad al "mensaje" de la obra - y repensar la politicidad desde otros espacios. Rancière lo postula en términos de la potencialidad de la experiencia estética como experiencia de disenso, que permitiría cuestionar el orden naturalizado de las cosas, la distribución de lo visible y lo invisible, de lo común y lo privado, de la palabra y el ruido (Rancière 201 l). Mouffe lo plantea en términos de la potencialidad de "hacer visible aquello que el consenso dominante tiende a ocultar y borrar" (Mouffe 2014: 99).

Si otrora la potencialidad político-crítica del arte callejero se circunscribió a la noción de libertad, crítica, transgresión, independencia y resistencia ante las instituciones - claramente en un contexto de descrédito de las propias instituciones -, el proceso que analicé nos muestra un camino que va añadiendo capas de sentido, desde la idea de ocupar espacios hacia la de disputar derechos destacando, asimismo, la precarización y auto-precarización que la primera estrategia suele conllevar. Argumenté que dicho proceso de resignificación debe ser visto, necesariamente, como un proceso de politización cultural, o sea, un proceso por el cual la propia práctica artística se erige como medio de disputa colectiva por derechos, que a su vez comunican ciertas maneras de conceptualizar el arte y sus potencialidades político-críticas.

La reivindicación del derecho a hacer arte callejero y a que el mismo no sea considerado un delito nos permitió analizar cómo los artistas se hicieron visibles como colectivo - no sin disensos - reivindicando su voz y sus formas de expresión para que sean reconocidas como tales. Estos artistas reclaman que sus estrategias de producción y reproducción artística - independientes - sean valoradas y no criminalizadas, pero que a su vez sean reconocidas como patrimonio cultural intangible de la ciudad, reivindicando al mismo tiempo otras modalidades de vida, otras formas de imaginar y habitar el espacio público con arte y otras modalidades de diseñar las políticas - legislaciones culturales que los atañen, de manera democrática y participativa. 


\section{BIBLIOGRAFÍA}

BECKER, Howard, 2008, Los Mundos del Arte: Sociología del Trabajo Artístico. Buenos Aires: Universidad Nacional de Quilmes.

BOURdieu, Pierre, 1995, Las Reglas del Arte: Génesis y Estructura del Campo Literario. Barcelona: Anagrama.

CALABRE, Lía, y Deborah Rebello LIMA, 2014, “Do do-in antropológico a política de base comunitária - 10 anos do programa Cultura Viva: uma trajetória da relação entre Estado e sociedade", Politicas Culturais em Revista, 2 (7): 6-25.

CINGOlani, Josefina, 2019, Pensó Que el Rocanrol Solo Era el Show: Consensos, Tensiones y Disputas en la Configuración del Circuito de Rock Platense. La Plata, Universidad Nacional de La Plata, tesis doctoral en Ciencias Sociales.

CHAUí, Marilena, 2013, Ciudadanía Cultural: El Derecho a la Cultura. Caseros: RGC Libros.

DEL MÁRMOL, Mariana, 2020, "Entre el deseo, la amistad y la precarización: trabajo artístico y militancia cultural en la producción teatral platense", Cuadernos de Antropología Social, 52 (1): 169-188.

DEL MÁRMOL, Mariana, Gisela MAGRI, y Mariana Lucía SÁEZ, 2017, “Acá todos somos independientes: triangulaciones etnográficas desde la danza contemporánea, la música popular y el teatro en la ciudad de La Plata”, El Genio Maligno - Revista de Humanidades y Ciencias Sociales, 20: 44-64.

GARCÍA CANCLINI, Néstor, 1987, "Introducción. Políticas culturales y crisis de desarrollo: un balance latinoamericano”, in Néstor García Canclini (comp.), Políticas Culturales en América Latina. México, DF: Grijalbo, 13-61.

Infantino, Julieta, 2014, Circo en Buenos Aires: Cultura, Jóvenes y Políticas en Disputa. Buenos Aires: Instituto Nacional del Teatro.

INFANTINO, Julieta, 2017, "De pasiones, compromisos e investigaciones de larga duración: potencialidades y límites en una investigación colaborativa con artistas (circenses)". Publicar - En Antropología y Ciencias Sociales, 23: 31-52.

INFANTINO, Julieta, 2018. "Working with circus artists: reflections on a process of collaborative research, participation and commitment". Conjunctions - Transdisciplinary Journal of Cultural Participation, 5 (1): 1-18.

INFANTINO, Julieta, 2019a, "Políticas culturales, arte y transformación social: recorridos, usos y sentidos diversos en espacios de disputa", in Julieta Infantino (comp.), Disputar la Cultura: Arte y Transformación Social en la Ciudad de Buenos Aires. Caseros: RGC Libros, 19-64.

INFANTINO, Julieta, 2019b, “Transformar, resistir, demandar: disputas político-culturales hacia una ley nacional de circo", in Julieta Infantino (comp.), Disputar la Cultura: Arte y Transformación Social en la Ciudad de Buenos Aires. Caseros: RGC Libros, 273-310.

LAMACCHIA, María Claudia, 2012, Otro Cantar: La Música Independiente en Argentina. Buenos Aires: Unísono Ediciones.

MOREL, Hernán, 2018, "Que siga el baile: clausuras y fomento a las milongas en la ciudad de Buenos Aires”, in Romina Sánchez Salinas y Julieta Hantouch (comps.), Cultura Independiente: Cartografía de un Sector Movilizado en Buenos Aires. Buenos Aires: RGC Ediciones, 171-192.

MOUfFe, Chantal, 2014, Agonística: Pensar el Mundo Políticamente. Buenos Aires: Fondo de Cultura Económica. 
RANCIÈRE, Jacques, 2011 , "Las paradojas del arte político", El Espectador Emancipado. Buenos Aires: Manantial, 53-84.

RICHARD, Nelly, 2011, "Lo político en el arte: arte, política e instituciones", Santiago de Chile: ARCIS University. Disponible en < https://hemi.nyu.edu/hemi/en/e-misferica-62/ richard $>$ (última consultación octubre 2021).

SÁEZ, Mariana, 2016, "Potencia de la contradicción", Boba, 2: 69-72.

SANTINI, Alexandre, 2017, Cultura Viva Comunitaria: Políticas Culturales en Brasil y América Latina. Caseros: RGC Libros.

SHORE, Cris, 2010, "La antropología y el estudio de la política pública: reflexiones sobre la formulación de las políticas", Antípoda, 10: 21 - 49.

TURINO, Celio, 2013, Puntos de Cultura: Cultura Viva en Movimiento. Caseros: RGC Libros.

VICH, Víctor, 2014, Desculturalizar la Cultura: La Gestión Cultural como Forma de Acción Política. Buenos Aires: Siglo Veintiuno.

WRIGHT, Susan, 1998, "La politización de la 'cultura'”, in Mauricio Boivin, Ana Rosato y Victoria Arribas (comps.), Constructores de Otredad: Una Introducción a la Antropología Social y Cultural. Buenos Aires: Antropofagia, 128-141. 